\title{
Cost Conscious? The Neural and Behavioral Impact of Price Primacy on Decision-Making
}

\section{Citation}

Karmarkar, Uma R., Baba Shiv, and Brian Knutson. "Cost Conscious? The Neural and Behavioral Impact of Price Primacy on Decision-Making." Journal of Marketing Research (JMR) 52, no. 4 (August 2015): 467-481.

\section{Published Version}

http://journals.ama.org/doi/full/10.1509/jmr.13.0488

\section{Permanent link}

http://nrs.harvard.edu/urn-3:HUL.InstRepos:28548032

\section{Terms of Use}

This article was downloaded from Harvard University's DASH repository, and is made available under the terms and conditions applicable to Open Access Policy Articles, as set forth at http:// nrs.harvard.edu/urn-3:HUL.InstRepos:dash.current.terms-of-use\#OAP

\section{Share Your Story}

The Harvard community has made this article openly available.

Please share how this access benefits you. Submit a story.

Accessibility 


\title{
Cost Conscious? The Neural and Behavioral Impact of Price Primacy on Decision-Making
}

\author{
UMA R. KARMARKAR \\ BABA SHIV \\ BRIAN KNUTSON
}

Uma R. Karmarkar is an Assistant Professor in the Marketing Unit of the Harvard Business School, Soldiers Field, Morgan 183, Boston, MA 02163 (ukarmarkar@hbs.edu). Baba Shiv is the Sanwa Bank, Limited, Professor of Marketing at the Graduate School of Business, Stanford University, Stanford, CA 94305 (shiv_baba@gsb.stanford.edu). Brian Knutson is an Associate Professor of Psychology and Neuroscience at Stanford University, 470 Jordan Hall, Stanford, CA 94305-2130 (knutson@psych.stanford.edu). This research was funded in part by National Science Foundation Grant 0748915 to B.K. The authors would like to thank Daniel Yoo and Andrew Trujillo for their assistance with data collection. 
Price is a key factor in most purchases, but can be presented at different stages of decision-making prior to a purchase. We examine the sequence-dependent effects of price and product information on the decision-making process at both neural and behavioral levels. During functional magnetic resonance imaging, the price of a product was shown to participants either before or after the product itself was presented. Early exposure to price, or price primacy altered the process of valuation, as seen via altered patterns of activity in medial prefrontal cortex immediately prior to purchase decisions. Specifically, while viewing products first resulted in evaluations strongly related to products' attractiveness or desirability, viewing prices first appeared to promote overall evaluations related to products' monetary worth. Consistent with this framework, we show that price primacy can increase purchase of bargain priced products when their worth is easily recognized. Together, these results suggest that price primacy highlights considerations of product worth, and can thereby influence purchasing.

Keywords: consumer behavior, price, fMRI, value, retail promotion, purchase decisions 
Imagine walking in to a department store. Suppose the first thing you see is a display with a sweater that catches your eye. When you walk over to it, you look at the tag to find a price of $\$ 49.99$. Now suppose that when you enter the store you first approach a rack of clothes labeled with a "\$49.99" sign. With this price in mind, you browse through the options and find a sweater that fits your taste. In both scenarios, you have the same information before choosing whether to head to the register. But are you going to be making the same kind of choice?

It would be reasonable to assume that information plays a fixed role in the computation of value and should be factored into a decision the same way, regardless of when it is encountered. However, early exposure to certain facts or attributes could also set a context for processing subsequent information, shaping product perceptions and choice behavior. When consumers attend to a product first, they are engaged affectively, and this liking (or disliking) reaction largely influences their perceptions of value and purchase decisions. Here we propose that attending to the price first, or price primacy, focuses consumers' on whether a product is worth a given price.

Disentangling constructs such as liking and value can be difficult with behavioral measures alone, since explicit tests of attribute perceptions may introduce additional biases in attitudes and behavioral intentions (Feldman and Lynch 1988). Functional magnetic resonance imaging (fMRI) can provide a unique and useful tool for addressing some of these challenges since it can be used to track the neural correlates of key decision components prior to choice without disrupting the process of decision-making. Thus we combined neuroimaging with behavioral measures with neuroimaging to explore predictions related to price primacy. 
Primacy and Sequencing Effects

Research on sequential presentation of information has shown that changing the order of information can influence a broad range of evaluative processes. "Primacy" of information, (presenting it first) can increase its salience, commanding greater attention, improving encoding in memory, and facilitating retrieval of related information (Asch 1946; Anderson 1973; Wyer and Srull 1986; Page and Norris 1998).

In the context of decision-making, studies on multi-option choice sets have shown that initial items in a series can dominate later items in part due to their relative advantage in being remembered (Mantonakis et al. 2009, Bruine deBruin 2005). In addition to memory-related effects, early options can set standards, expectations, or reference points by which all later options are then benchmarked (e.g. Bruine deBruin and Keren 2003).

Order effects can also influence how information or certain attributes contribute to making a choice. Early consideration of an attribute can amplify its impact on subsequent judgment and decision-making (Feldman \& Lynch 1988; Tavassoli \& Lee 2004; Johnson et al. 2007; Weber et al. 2007). Furthermore, when determining product preferences, initial attributes can bias the interpretation of, or even the consideration given to, the information presented afterwards (Russo et al. 1998; Yeung and Wyer 2004).

Across this literature, it becomes clear that order effects can influence the way a decision unfolds. Initial information can be overweighted, dominating the rest of the choice process, or it can engage a particular strategy (or perspective) that frames later evaluations. Building from this, we propose that changing the sequence in which price and product information are encountered 
will change the decision-making process. To better understand how this might occur, we turn our attention to how product and price information contribute to preference formation and value estimates.

\section{Product Preference Formation}

Extensive research has demonstrated that exposure to a stimulus (or product) results in immediate affective preference formation (e.g. Zajonc 1980). Furthermore, evidence indicates that both previously established preferences and novel evaluations arise automatically, suggesting that it may not be possible for a consumer to avoid experiencing positive or negative affect when they see a product (Fazio et al. 1986; Bargh et al. 1992, Duckworth et al. 2002). Consistent with this, fMRI studies of yes/no purchase decisions in which products are shown before prices have revealed that a product's evaluation is dominated by its initially evoked desirability, or how much it is liked or disliked when it is first encountered (Knutson et al. 2007).

Price, Preference and Estimating Value

How could early exposure to price information differentially influence this process? Despite (or perhaps because of) its quantitative nature, a price alone is difficult to evaluate without points of reference (Hsee et al. 2003; Hsee, Rottenstreich and Xiao 2005). In fact, consumers typically draw from a range of additional information when called upon to interpret prices (e.g. Ariely, Lowenstein and Prelec 2003; Simonson and Drolet 2004). These findings might imply that price information will be integrated with product information in the same way regardless of their order, and so price primacy should have minimal effects on valuation and choice. 
Even when presented alone, however, price represents what the consumer will lose in a transaction. Anticipating or incurring this cost may even elicit a physical "pain of paying" (Prelec and Loewenstein 1998; Knutson et al. 2007; Rick et al. 2008). According to this account, price primacy might initialize a transaction with a negative valuation or loss frame. By this reasoning, early exposure to price would overweight potential costs associated with a product. This "loss frame" hypothesis further predicts price primacy could reduce perceptions of product value and/or attractiveness, potentially resulting in decreased purchase rates.

The price literature reviewed above generally implies that price primacy should only exert a quantitative influence on the weighting (or saliency) of price within a constant calculation of value. But we can also explore the possibility that it has qualitative effects on the value calculation (or purchase criteria) itself. Beyond conveying costs, price information can invoke considerations of the utility, benefit-cost balance, or overall worth of a product (e.g. Thaler 1999). Indeed, individuals commonly associate price and worth so strongly that prices can not only establish expectations of an item's value (Rao and Monroe 1989), but can even influence an item's experienced quality or functionality during its consumption (Shiv, Carmon, and Ariely 2005; Waber et al. 2008; Plassmann et al. 2008). Thus while product primacy initializes the decision with the affective attractiveness of a product, price primacy could initialize it with considerations of whether the product will be worth its price.

A price tag presented in advance of an associated product may not be sufficient to set specific value expectations on its own. More broadly though, it could focus the evaluation process on a product's utility, potentially resulting in a different scale or criterion for determining value. Thus we predict price primacy may not influence how much people desire a subsequently presented item, but rather the manner in which they integrate that product's 
desirability with price information to form a comprehensive estimate of its worth. Such a shift goes beyond simple predictions of order effects in which price might be weighted more heavily as an independent factor in the calculation of value. Instead, it is in line with research indicating that early information can determine the evaluative criteria used in decision contexts (e.g. Bruine de Bruin and Keren; Yeung and Wyer 2004; Russo et al. 1998; Yeung and Wyer, 2004).

To summarize, we approach the question of whether the order of product and price information can influence the mechanisms underlying the choice process, and ultimately purchasing decisions themselves. We propose the following hypotheses:

\section{H1: Changing the sequence in which price and product information are encountered changes the decision-making process.}

\section{H2: In contrast to "product primacy", price primacy causes a qualitative shift in how product value is determined, increasing considerations of an item's (monetary) worth.}

Testing these hypotheses presents some challenges, as we are positing a change in the ways that value-related mechanisms operate as information is encountered over time. While behavioral measures can provide some insight regarding general trends in preferences, some mechanistic changes may not be consciously accessible, particularly at different stages of the decision process. We thus turned to fMRI based on its ability to record signals simultaneously from multiple neural loci that represent different facets of value while a choice is underway.

Neural Correlates of Value and Preferences 
Recent research in decision neuroscience allows us to focus on at least two brain areas whose activity correlates with an item's desirability (e.g. liking) and its value respectively. This suggests that fMRI has the potential to test our hypotheses and to address the alternative ones (e.g. no change, loss framing, differential weighting of value).

Most central to our hypotheses are the mechanisms involved in the monetary value of an item. Willingness-to-pay (WTP) has been correlated with levels of activity in overlapping regions of medial orbitofrontal and prefrontal cortex (Plassmann, O’Doherty, \& Rangel, 2007, 2010). Work by Knutson et al. (2007) found that the degree to which individuals perceived product offers to be a bargain (or overly expensive) correlated specifically with activity in medial prefrontal cortex (MPFC). This is consistent with a broader set of findings in which MPFC and neighboring regions appear to integrate information, including product attributes or choice set composition to reflect the overall value of one or more items (Knutson et al. 2001, 2007; Hare et al. 2008; Hare, Camerer, \& Rangel 2009; Smith et al. 2010, Levy \& Glimcher 2012).

Based on these findings, we selected MPFC as a "region of interest" (ROI) for our analysis, and suggest that activity patterns correlated with perceived value in this brain area will differ based on price versus product primacy. While this could be expressed as an overall decrease or increase in MPFC signal during the decision process, our hypotheses suggest a more qualitative change. Thus the average response across items that yield distinct decision outcomes (e.g. evoke low values vs. high values) may not be sufficiently informative ${ }^{1}$. To understand the full range of potential changes to evaluative mechanisms within the context of choice, we look at

\footnotetext{
${ }^{1}$ As an example, suppose that focusing attention on worth had an amplifying (multiplicative) response. This could magnify increases in signal correlated with high value, and decreases in signal correlated with low value compared to product primacy. However, the average signal in both cases might be the same. Thus it is important to not only look at the overall response, but to look at the response to two meaningfully distinct decision categories.
} 
how price primacy influences the value signal for items that are purchased, compared to those that are not purchased.

Though we make direct predictions about overall value, price primacy might also influence the automatic affective response to the product itself. Thus a second region of interest is the nucleus accumbens (NAcc), whose activity has been shown to correlate with the attractiveness, or expressed preference for an item. In particular, the NAcc appears to represent the anticipated reward value of monetary gains, prizes and various products (e.g. Knutson et al. 2001, 2007 2008, Erk et al. 2002, but see also Hare et al. 2008). Our hypotheses (H1,H2) do not address how price primacy might change the perceived attractiveness of a product, or by extension activity in the NAcc. However, it is also our goal to rule out competing predictions such as those generated by loss framing and/or price evoking pain associated with the transaction, which might suggest that early attention to price might decrease product value or desirability. Thus we predict that early exposure to price will not decrease the MFPC or NAcc response to the offered products.

To summarize here, to examine the effects of price primacy on decision-making we chose to analyze two specific regions of interest (ROIs) correlated with product value and product attractiveness. In support of our psychological predictions, we make the following neural predictions:

\author{
H3a: Activity patterns correlated with perceived monetary value in MPFC \\ for purchased and unpurchased products differ based on price versus \\ product primacy.
}




\section{H3b: Price primacy does not decrease overall activity correlated with product value in MPFC and preference (liking) in NAcc.}

The results of this research are important not only from a theoretical perspective, but also from a managerial one. The availability and timing of price information during purchase decisions is increasingly under a firm's control, in promotional displays, store design, and particularly online (e.g. e-commerce websites). Thus the effects of price versus product primacy are relevant considerations for marketers in the design of nearly any retail experience.

With these contexts in mind, we designed a follow-up study connecting the processrelated findings of the fMRI experiment more directly to their potential impact on consumer purchasing behavior. Previous research suggests that congruence between the features of a message and important attributes of a product can facilitate purchasing (Lynch \& Wright, 1995). If, as hypothesized, price evokes considerations of utility and worth, then price primacy might facilitate purchases whose worth is easily established. We chose to test this possibility directly using utilitarian products, since their value is defined by their "utility", practicality, and indeed their worth (Strahilevitz and Myers 1998; Dhar and Wertenbroch, 2000; Okada 2005).

\section{H4: Price primacy increases the likelihood of purchasing products that are perceived (recognized) as utilitarian.}

We use these findings to better validate the marketing implications of the fMRI work and to support an overall psychological account of price primacy. 


\section{EXPERIMENTAL METHODS}

Participants. Twenty-four total participants completed the scanning task. Seventeen of these (ages 19-27; 9 females) were included in the final fMRI analysis. Six participants were excluded since they purchased fewer than four items per condition and therefore failed to provide sufficient data to model. As is the norm in fMRI studies, one participant was excluded due to excessive head motion (i.e., more than $2 \mathrm{~mm}$ from one whole brain acquisition to the next during or between runs).

Procedure. Prior to entering the scanner, participants received instructions about the task and were tested for task comprehension in two practice trials. Participants were provided with their compensation of $\$ 40.00$ cash to put in their pocket before entering the scanner; these funds were at their disposal to spend on products during the experiment. After entering the scanner, participants engaged in two sessions of the task, each consisting of 40 trials, reflecting a total of 80 offered products. During price primacy trials, participants viewed a price (period 1), followed by a product and the price together (period 2), and then made their decisions by pressing buttons indicating yes or no (period 3; Figure 1). In product primacy trials, the product was presented alone during period 1 , followed by a product and the price together (period 2) and a decision period (period 3). Each period lasted 4 seconds and a fixation cross was presented for 2 seconds between each trial, building on a previous neuroimaging study of single item purchasing (Knutson et al. 2007). Using an event-based design, both trial types were pseudorandomly mixed within sessions. Session order, and assignment of a particular product to the price or product 
primacy condition were counterbalanced across participants, resulting in four possible pseudorandom trial sequences to which participants were randomly assigned. No behavioral or neural differences were found between sequences, thus data from all participants were pooled.

The experiment was incentive compatible, to ensure that price information was meaningful and relevant. Two trials (one per session) were selected at random to count "for real" at the end of the session. Participants who had chosen to purchase the products that they viewed during those selected trials paid the offered price from their endowment and received their products by mail. Those who chose not to make purchases retained all of their funds. Products ranged in retail price from $\$ 8.00-\$ 80.00$; but to encourage purchasing, prices were discounted by up to $80 \%$. Participants were aware that the prices were discounted, but did not know by how much.

After exiting the scanner, participants completed a survey in which they viewed the images and descriptions of each product that had been used in the main experiment (without price information) one at a time and rated their liking for each one a scale from 1 [Do not like] to 7 [Like very much]. In a separate survey, participants viewed the images and descriptions of each product together with their true retail prices (one at a time), and rated their willingness-topay (WTP) for each item as a percentage of its associated retail price. The WTP rating process after scanning was not separately incentivized.

FMRI acquisition and analysis. All participants were right-handed and fluent in English with no history of neurological disorders. Participants were screened for any metal or magnetically reactive substances present in or on the body prior to scanning. Images were acquired with a 1.5-T General Electric MRI scanner, with whole brain volumes acquired every 
two seconds (2s TR). (See web appendix for full description of scanning parameters.) Analyses were conducted using Analysis of Functional Neural Images software (AFNI ; Cox 1996).

For the whole brain analyses, linear regression models were used to analyze the blood oxygenation level dependent response (henceforth referred to as "activation" or "activity"). Whole brain FMRI data recorded across the duration of the experiment were modeled with the following regressors of interest: (1) trial condition (price vs. product primacy), (2) individualized liking regressors derived from post-scan ratings (converting responses from the 1-7 Likert scale to a -3 to +3 scale) and (3) individualized price differential or "worth" regressors, calculated by subtracting each item's offered price from the individual's willingness to pay, all expressed as a percentage of retail price. Liking and price differential were modeled simultaneously during period 2 to ensure that each regressor would account for unique variance in brain activity over the same time frame, allowing separate examination of each factor. The model additionally included the following regressors of "noninterest": purchase decision, reaction time, interactions between trial condition and the other preceding variables, temporal periods and six motion regressors.

Whole brain maps were thresholded at $\mathrm{p}<.001$ (uncorrected) to identify significant spatial areas of activation, with a four voxel cluster threshold (of $4 \mathrm{~mm}$ cubic voxels, alpha level of .001). For MPFC activity, small volume correction was used to confirm activation based on functionally selected activity peaks (maximum beta; see Web Appendix for further detail). These analyses allowed us to identify and confirm that activity in specific brain areas were correlated with specific decision components (e.g. liking and price differential).

A separate set of analyses directly examined the activity in our hypothesized (preidentified) regions of interest. For each individual we examined the signal taken from $8 \mathrm{~mm}$ 
spherical regions centered on the NAcc and MPFC at the following a priori designated coordinates: NAcc: $\pm 12,10,-2$ and MPFC: $\pm 4,53,-6$ (Knutston et al. 2007). From this, the percent signal change over time was averaged over purchase and nonpurchase product and priceprimacy trials within-subjects, yielding four averaged time courses. Activity timecourses were lagged by 4 seconds to compensate for the lag in hemodynamic response and compared across participants at predicted peak activation time points with paired t-tests.

We further tested for differences-in-differences between activity evoked by purchased and unpurchased products in the NAcc and MPFC ROIs for period 2 (when both product and price were visible to the participant). Average activity (in units of percent signal change) for all trials for all participants was regressed on condition (price/ product primacy), purchase (yes/no), their interaction, and subject fixed effects.

RESULTS

Behavior. On average, participants chose to purchase $27 \%$ of the eighty offered products $(M=21.29, \mathrm{SD}=11.56)$. As a measure of perceived value, price differential or consumer surplus was calculated by subtracting participants' WTP rating (as a percent of retail) from each product's the price offered during the scan (also as a percent of retail). Thus a positive price differential percentage meant that participants perceived a product to be a good value (or bargain), while a negative price differential meant that participants perceived a product to be expensive. Indeed, price differential was, on average, positive for purchased items $(M=27.8 \%$, $\mathrm{SD}=18.2)$, and negative for unpurchased items $(M=-2.1 \%, \mathrm{SD}=12.8 ; p<.001)$. Interestingly, price differential for purchased items was significantly lower in price primacy trials $(M=25.9 \%$ 
$\mathrm{SD}=18.59)$ compared to product primacy trials $(M=29.7 \% \mathrm{SD}=18.32, p<.02)$ but still positive in both cases. This suggested that participants saw their purchased items as a bargain in both conditions, but more so in the product primacy condition.

Despite this decrease in magnitude, the average number of items with a price differential of zero (accepted price) or higher (bargain) was identical between conditions $\left(M_{\text {Price }}=20.94, S D\right.$ $\left.=1.97 ; M_{\text {Produc }}=20.94, S D=1.99 ; p=1\right)$. For the products with positive price differentials $(>=0)$ we also examined "conversion rates", or the percentage that were purchased, and found no significant differences $\left(M_{\text {Price }}=46 \%, S D=.196 ; M_{\text {Product }}=42 \%, S D=.21 ; \mathrm{p}=.25\right.$, paired ttest.)

Similarly, the number of products purchased did not significantly differ as a function of presentation order $\left(M_{\text {Price }}=11.06, \mathrm{SD}=5.38 ; M_{\text {Prod }}=10.23, \mathrm{SD}=6.63 ; p=.34\right)$, nor did the average price of purchased products $\left(M_{\text {Prices }}=8.58, \mathrm{SD}=1.24 ; M_{\text {Prod\$ }}=8.47, \mathrm{SD}=1.58 ; p=\right.$ .76). As expected, liking ratings were higher for purchased $(M=5.79, \mathrm{SD}=.71)$ as compared to unpurchased products $(M=3.37, \mathrm{SD}=.61 ; p<.001)$. However, liking for purchased products did not differ between product and price primacy $\left(M_{\text {ProdLike }}=5.85, \mathrm{SD}=.75 ; M_{\text {Pricelike }}=5.72, \mathrm{SD}\right.$ $=.80 ; p=.35)$. Overall, these findings suggest that while participants may have changed their valuation process to be more critical or conservative under price primacy, this did not decrease their liking for products, or their likelihood of purchase.

Neural activity: product value. As a "neural manipulation check", we conducted whole brain analyses to confirm that we observed meaningful areas of brain activity correlated with monetary value. To do this, price differential ratings were modeled while both product and price information were presented (period 2). Focusing on this part of the trial allowed direct 
comparisons between conditions and avoided contamination from post-choice effects. Whole brain analysis revealed correlated activity localized in the prefrontal cortex (Table 1), as well as significant activation of MPFC as predicted (Figure 2A). These findings suggest that MPFC tracked price differential when participants were viewing price and product information together on the screen. It also replicates previous work demonstrating the role of MPFC in integrating price and product information (e.g. Knutson et al. 2007,2008; Plassmann et al. 2007; Hare et al. 2008).

Given this validation, an anatomically defined a priori ROI analysis was used on the raw data (see Methods) to independently test the condition-dependent activity in MPFC. There was no difference in the average timecourses for price primacy trials compared to product primacy trials at any point of the trial, countering the possibility of a quantitative main effect or decrease in value due to overweighting costs (Figure 2B, H3B). To examine whether price primacy might be altering the evaluation process as it relates to choice, we examined the conditions by response to purchased and unpurchased products. As can be seen from the timecourses plotted in Figure 2C, MPFC responded in different ways depending on the order of information presented. In product primacy trials, neural activity increased significantly more in MPFC for products that were eventually purchased compared to those that were not when product and price information were both on the screen (p2), as indicated on the left graph of Figure $2 \mathrm{C}(p<.05$, paired t-tests). However, this finding no longer held in price primacy trials. Despite a moderate increase in MPFC activity for purchased items during the trial (Figure 2C), the difference in activity for eventually purchased and unpurchased items in period 2 did not reach significance.

Regression analysis of the average peak MPFC activity for the four seconds when price and product information were visible prior to choice (p2) formally tested these effects for a 
difference-in-differences between product and price primacy (Table 2). The significance of the condition-by-purchase interaction coefficient $(p<.05)$, suggested a qualitative difference between conditions. Further, examination of the neural response to items that were not purchased revealed that MPFC activity decreased during period 2 in the product primacy condition but remained close to baseline in the price primacy condition (Figure 2D, $p<.05$, paired t-test). Notably, this finding also argues against loss or cost amplification predictions, by showing that value for unwanted items is actually "less negative" under price primacy. .

Neural activity: product desirability. We again used whole brain analyses to confirm that activity in NAcc correlated with product desirability by modeling preference (liking) ratings when the product and price were presented together. This analysis indeed revealed that NAcc activity scaled with product liking (Figure 3A), consistent with previous evidence that NAcc activity tracks anticipated reward and product preference (Knutson et al. 2001, 2007, 2008; Erk et al. 2002). Neural activity correlated with liking was also found in the adjacent caudate (Table 1), which has been linked to reward-motivated behavior (Balleine, Delgado and Hikosaka 2007) and in the anterior cingulate cortex, thought to be involved in conflict monitoring and decision difficulty (Bush, Luu and Posner 2000; Pochon et al. 2008) among other processes.

Analysis of independently specified a priori ROI data across all products for the entire trial demonstrated that price primacy did not decrease the signal in NAcc (Figure 3B, H3B). Indeed, at one of the timepoints when price and product information were visible, activity in price primacy trials was significantly greater than product primacy. To better understand how this could occur, we examined activity related to purchase outcomes. In product primacy trials, NAcc activity increased for items that were eventually purchased and decreased for products that 
were eventually not purchased (Figure 3C, left). This difference arose when products first appeared (period 1). In price primacy trials, a comparable pattern of activity occurred in response to later product presentation in period 2 (Figure $3 \mathrm{C}$, right). It is notable that in both cases, the onset of the NAcc response was locked to the first appearance of the product, suggesting that NAcc activity responded specifically to the item under consideration rather than other more general decision biases or action plans.

Regression analysis of period 2 (Table 2) confirmed that the coefficient of the interaction term for condition-by-purchase was not significant $(p=.652)$, suggesting that NAcc similarly differentiated between eventually purchased and unpurchased items at this time regardless of trial type. However, examination of the responses to unpurchased items indicated slightly less of a decrease during price-primacy trials (Figure $3 \mathrm{D}, p<.05$ ). This implies that seeing prices first may have caused participants to have a more neutral affective response to products they eventually did not choose.

\section{DISCUSSION}

Our findings demonstrate that the ordering of price and product information can alter the product evaluation process (H1). Behaviorally, price primacy could appear to have simply reduced items' perceived attractiveness or value, since purchased products elicited lower (though still positive) price differentials. However, participants bought the same number of items, and had similar liking ratings (reflecting similar product desirability) across conditions. Thus it is possible that participants found products similarly attractive in both situations, but were more critical of their value under price primacy (consistent with H2). Importantly, these findings also 
support the assumption that liking and monetary value are meaningfully distinguishable during the decision process.

To gain a more nuanced understanding of price primacy's effects we turned to the neural data and related hypotheses. Supporting H3B, price primacy did not cause a "main effect' decrease in activity in MPFC or NAcc during any part of the trial, suggesting that price did not simply shift these value signals down (or up) in a quantitative manner. Instead, as predicted, the strongest sequence-dependent effects occurred in MPFC, a region whose activity correlated with perceived product worth $(\mathrm{H} 3 \mathrm{~A})$. In product primacy trials, consideration of items that were eventually purchased increased MPFC activity while eventually unpurchased items decreased it. This pattern of responses could be interpreted as a general value integration process that utilizes a scale ranging from positive (increased value) down to negative (decreased value) endpoints. In price primacy trials, however, activity increased moderately for purchased items but did not decrease for unpurchased items. This suggests a modification of the general value scale, which ranges from positive (increased value) down only to zero (no value, or no interest). In this case, we surmise that items that surpassed some "sufficient" level of worth were then purchased, while those that were not valued were not. Indeed, given that NAcc activity for unpurchased items also decreased less in price primacy trials, one possibility is that individuals simply ignored those products rather than actively rejecting them. Furthermore, truncation of the general valuation scale under price primacy (e.g., from "liked" to "sufficient") is in accordance with the observed decreased price differential even in the face of unchanged liking ratings.

These findings suggest a novel account of price primacy surpassing the conclusions that could be drawn from behavior alone. Price primacy appears to encourage individuals to critically evaluate whether a product is worth its attendant price, rather than simply evaluating the product 
first on the basis of its attractiveness (H2). However, we are mindful that care must be taken when inferring behavioral function from brain data (e.g. Poldrack \& Wagner 2004), In addition, for the purposes of marketers, it is useful to understand how such mechanistic changes do or do not influence purchase behavior when information is presented in different sequences to consumers, and these behavioral results are often examined on larger sample sizes. Given these considerations, we conducted a "validation" study to examine some of the more nuanced predictions made by the fMRI findings.

PRICE PRIMACY AND UTILITARIAN PURCHASES

Since product and price primacy lead to different types of evaluation, their influence on purchase may depend on the nature of the products under consideration. Utilitarian products are commonly defined as having practical or functional uses (e.g. Strahilevitz and Myer 1998) which allows them to have an evident and easily justified worth (Dhar and Wertenbroch 2000; Okada 2005). Our framework suggests that under price primacy, consumers make their purchasing decisions by evaluating whether a product is sufficiently worth its price. We therefore predict that price primacy could increase purchases of utilitarian products compared to product primacy, since its evaluation criteria aligns better with the product merits (see also, H4). The following experiment tests this possibility directly.

\section{Methods}

Eighty-three participants from a national sample (ages 18-79, $56 \mathrm{~F}$ ) took part in an internet study compensated by lottery drawings for gift certificates to an online retailer. 
Respondents were randomly assigned to either the product primacy or price primacy condition in a between-subjects experimental design. Similar to the fMRI study, participants assumed an endowment of $\$ 15$ for each decision, and were offered four utilitarian products at discounted prices. Participants viewed only a price or only a product (image and product name) for $8 \mathrm{~s}$ and then a decision screen displaying both price and product. Using slider on a scale from 0 [Do not want to buy] to 100 [Definitely want to buy], participants indicated whether they did ( $>=50)$ or did not $(<50)$ want to buy the item. After this purchase process, participants viewed the names of the four items (without pictures) and reported their WTP for each one by typing in a dollar amount. This procedure differed from the "percentage of retail" process used in the fMRI experiment to allow participants to generate their own values without using an explicit reference point.

Participants were informed their decisions potentially had real consequences at the beginning of the experiment. To implement incentive compatibility, four individuals were randomly selected, independent of the compensation lottery, to have one of their choices realized (as in the fMRI study). If they had chosen to purchase the product, it was delivered by mail and they received the remaining amount of the endowment (minus the item's price) as credit to a popular online retailer. Participants who had chosen not to purchase received the entire $\$ 15$ endowment credit. Finally, participants read definitions for frivolous (hedonic) or practical (utilitarian) products adapted from Strahilevitz \& Myers (1998):

Frivolous Products: Bought for pleasure-oriented use. Something fun, experiential, and perhaps even decadent. Purchasing these goods or these kinds of 
services might be seen as a guilty pleasure. One example might be a bottle of champagne.

Practical Products: Bought for goal-oriented use. Something that you ordinarily buy to carry out a necessary function or task in your life. Buying these doesn't cause any guilt because they are things you need. One example might be toilet paper.

Participants were asked to categorize each product viewed as frivolous, practical, frivolous and practical, or neither frivolous nor practical.

\section{Results}

Products were selected to be explicitly utilitarian in nature, and included a water filtration pitcher, AA batteries, a USB drive, and a flashlight. For any individual product, price versus product primacy had no effect on the frivolous/practical item categorization measure (Table 3). Thus, to ensure that participants' perceptions of the products were consistently utilitarian only individuals who rated all four items as "practical" or "frivolous and practical" were included in further analyses $(\mathrm{n}=61$, Ages $18-79 ; 41 \mathrm{~F})$. Examining the total number of purchased items (purchase intention scores $>=50$ ) showed that purchased rates were significantly higher in the price primacy condition $(M=2.61, S D=1.05)$ compared to the product primacy one $(M=1.83$, $S D=1.17 ; p<.01$, Students t-test), as predicted by H4 (Figure 4A).

Price differential was calculated here as the simple difference between the elicited WTP and the listed price in the offer. Price differential across products did not show a significant 
difference, though directionally the average was lower for price primacy, as had been seen in the fMRI results $\left(M_{\text {Price }}=\$ 2.70 ; \mathrm{SD}=3.30 ; M_{\text {Product }}=\$ 4.48, \mathrm{SD}=5.39 ; p=.126\right)$. In addition, the average number of products with a price differential of zero or greater did not differ between conditions $\left(M_{\text {Price }}=2.74, S D=1.24 ; M P_{\text {roduct }}=2.97, S D=1.19 ; p=.473\right)$ However, as shown in Figure 4B, examining the relationship between price differential and purchase in this study showed that under price primacy, participants were more likely have purchased items for which they had a price differential $>=0\left(M_{\text {Price }}=79 \% ; M_{\text {Product }}=52 \% ; p<.002^{2}\right)$. Notably, this provides strong support for our framework, as it demonstrates that under price primacy, estimates of value more accurately correlate with purchase decisions, suggesting that the worth of the product is indeed playing a bigger part in the decision than under product primacy.

\section{GENERAL DISCUSSION}

As a whole, these findings demonstrate that the sequence of information during a purchasing decision can alter the mechanisms underlying product evaluation and can also influence choice behavior. In a neuroimaging experiment, price primacy altered patterns of activity in MPFC in a manner suggesting that products were being evaluated based on whether they were sufficiently worth their price more than how much they were liked (or disliked). This apparent focus on worth was consistent with the overall behavioral results indicating that participants had somewhat more critical estimates of purchased products' value under price primacy even though their liking for the products did not decrease. As independent validation for this relationship between justifiable, or sufficient worth and purchasing, we found that price

\footnotetext{
${ }^{2}$ This analysis excludes three participants whose price differentials were negative for all four offered products.
} 
primacy could in fact increase purchase rates for products with recognized utility. In fact, we found that the relationship between purchasing and self-reported estimates of positive worth was more tightly correlated under price primacy than product primacy. Colloquially, our findings suggest the price primacy shifted participants' purchasing question from "Do I like it?" towards "Is it worth it?"

Critical to our framework, price primacy had a distinct effect from product primacy on the valuation of products that were eventually not purchased. Under product primacy, neural activity in MPFC and NAcc decreased for items that were eventually not purchased, consistent with assigning decreased value to those products. However, under price primacy, neither brain region showed diminished activity for items that were eventually not purchased. This finding suggests that price primacy may cause people to simply exclude less desirable items from consideration rather than actively devaluing them. The data and our interpretation differs from one in which price primacy increases the salience or weighting of losses, or decreased value due to increased painfulness of paying, since that would be expected to decrease MPFC and/or NAcc activity (e.g. Tom et al. 2007). Furthermore, neither product liking nor purchasing decreased under price primacy in the neuroimaging study, as might occur under a loss frame.

In addition to merely representing costs or loss in a rational sense, the "pain of paying" theory argues that price can elicit an aversive response akin to physical pain (Prelec and Loewenstein 1998, Rick et al. 2008). The results for NAcc and MPFC indicate that even if price primacy evoked pain early in the decision process, that pain did not systematically lower estimates of product value, nor did it prevent or decrease purchases. We can also examine whether there is evidence for price-evoked pain elsewhere in the brain. Prior neural research supporting pain of paying suggests the anterior insula, a region involved in processing pain and 
negative emotions (Coghill et al. 1994, 1999, Calder, Lawrence and Young 2001), shows increased activity in anticipation of not purchasing products (Knutson et al. 2007). Despite using identical discounts and replicating the design of that study in the product primacy trials, we did not find evidence linking increased insula activity directly to unpurchased products, nor did insula correlate with price differential (see Appendix). Though we do not find a significant role of this theory in the current study, questions of how and when price information may induce pain (or the anticipation of pain) and how such pain might influence perceived value remain important domains for further investigation.

Our hypotheses build on the theory that price can be representative of value or utility in a broader sense than costs (Thaler 1999) and that price sets expectations of product worth (e.g. Rao and Monroe 1989). Indeed, for products like wine or medicine, whose "utility" is difficult for non-experts to evaluate objectively ${ }^{3}$, price information directly influences the perceived quality of the consumption experience (Shiv, Carmon, and Ariely, 2005; Waber et al., 2008, and Plassman et al., 2008). Our results complement these studies, demonstrating that price can evoke general considerations of worth, even before the specific product is known. Furthermore, it shows that these considerations can dominate the decision process before consumption ever happens. Future directions for this work would be to concretely tie these findings together by examining the effects of price primacy on post-choice consumption experiences and satisfaction particularly in situations when the price-implied quality is noticeably different from the experienced quality.

\footnotetext{
${ }^{3}$ These goods could be considered a combination of experience and credence goods in that their evaluation is often dependent on both the user's experience but also on information/assurances provided by outside sources.
} 
We would expect the observed shift in evaluation mechanism, from liking to worth, to generalize to other price ranges, or categories of goods. However, the specific downstream influence of price primacy on purchasing behavior may depend on certain boundary conditions. Across studies, participants were aware that prices had been discounted. In the behavioral experiment, when participants were able to freely enter their WTP, their average price differential was positive $(M=\$ 3.58)$, suggesting that they perceived the products to be good values. Thus, the present findings may rely upon initial perceptions of prices as reasonable, "good" or even bargain prices. Still, all experiments were incentive compatible, and price differential values for unpurchased items in the neuroimaging experiment were negative, suggesting that participants did not dismiss the price information, and indeed considered some prices to be excessive. Participants also clearly attended to potential costs, expressing reluctance to give up their endowment during debriefing, even to obtain highly desirable products.

Given the limitations of the current study, future research would benefit from examining the influence of price primacy on purchasing in different types of value contexts, particularly ones where the expectation is that prices are expensive. For example, if consumers are aware that they are paying full retail prices in a brick and mortar store, an increased focus on worth might be predicted to decrease purchasing, since consumers might have difficulty justifying not searching for a better value. That could be contrasted with situations in which base prices are known to be (unavoidably) high. In this situation, our framework suggests that a focus on worth might decrease the consideration set (reducing the number of items with positive price differential) but increase purchase likelihood for the items that were recognized as sufficiently worthy. 
Overall, these findings demonstrate that the assessment of value from product and price information partially depends upon the order of their presentation. In a similar vein, "query theory" research proposes that the sequence of processing options can determine different choice outcomes. In query theory, decisions can be broken down into a series of internal memory queries, and the ordering of these queries can alter preferences or value estimates (Johnson et al. 2007; Weber et al. 2007). This framework has primarily been applied when sequential information relates to the comparison of two distinct options, rather than decisions about different attributes of single items. Unlike the current account, query theory assumes that the basic evaluation process remains constant regardless of order. Differences in estimated value instead arise because the initial query interferes with the impact of subsequent queries. In addition, explicit memory and retrieval play a crucial role in query theory, while the current decision scenarios do not require access of explicit memories (since all relevant information is provided on the screen). Accordingly, our participants did not show significant recruitment of regions commonly implicated in memory retrieval such as the hippocampus or parahippocampus (Squire 1992). Thus, while query theory's order effects appear similar to the present findings on some dimensions, the underlying neural mechanisms and behavioral consequences likely diverge. This further suggests that additional study is needed in understanding how the timing of different kinds of information, such as attributes or options, can influence choice.

The use of time resolved neuroimaging (e.g., fMRI) uniquely afforded visualization of participants' reactions to different decision elements, as well as exploration of the impact of these elements on purchasing. In typical studies of economic decision-making, liking and price differential (or WTP) can be considered inseparable and are assumed to reflect a common underlying dimension of preference. Here, while relative desirability of the items was 
represented faithfully in NAcc regardless of the ordering of information, the estimated monetary value of these items and correlated MPFC activation changed as a function of price primacy. By extension, NAcc activity might represent a context-independent element of preference that can be distinguished from the more context-dependent overall value of an item represented in the MPFC. Since purchasing of the same item can take place in numerous and varied situations, it will be important for future work to examine the degree to which the stable element in the NAcc response might facilitate prediction of a decontextualized demand for products (e.g. Berns and Moore 2011), allowing more strategic product-related decisions on the part of the firm.

From a marketer's perspective, the effects of price and product primacy are of particular importance in shopping contexts in which the flow of information is largely determined for the consumer, such as online retailing and e-commerce. If firms can offer good or bargain prices for utilitarian products, these findings suggest distinct sales benefits to making price salient early on. Conversely, when consumers will be seeing prices first, highlighting products' functionality may also increase purchases. The findings additionally suggest a caveat though - since price primacy may decrease willingness-to-pay, and may generally increase critical evaluations of worth, its benefits might be nullified by minor or misleading promotions.

In conclusion, we show that simply changing the order of price versus product information can exert meaningful effects on overall product valuation as well as purchase decisions by shifting the basis for product evaluation. These insights not only clarify how individuals make daily decisions, but also help predict how they might choose in novel situations involving different product categories. 


\section{REFERENCES}

Anderson, Norman H. (1973) "Serial Position Curves in Impression Formation.” Journal of Experimental Psychology 97(1):8-12.

Ariely, Dan, George Loewenstein, and Drazen Prelec. (2003), "Coherent Arbitrariness: Stable Demand Curves Without Stable Preferences." Quarterly Journal of Economics, 118 (1), 73-105.

Balleine, Bernard W., Mauricio R. Delgado, and Okihide Hikosaka. (2007) “The Role of Dorsal Striatum in Reward and Decision-Making” Journal of Neuroscience 27(31): 8161-65.

Bargh, John A., Shelley Chaiken, Rajen Govender, and Felicia Pratto. (1992) "The Generality of the Automatic Attitude Activation Effect." Journal of Personality and Social Psychology 62(6): 893-912.

Berns Greg S. and Sara E. Moore. (2011) “A neural predictor of cultural popularity.” Journal of Consumer Psychology 22(1): 154-160.

Bruine de Bruin, Wändi. (2005) "Save the last dance for me: Unwanted serial position effects in jury evaluations." Acta Psychologica 118:3: 245-260.

Bruine de Bruin, Wändi, and Gideon Keren. "Order effects in sequentially judged options due to the direction of comparison." Organizational Behavior and Human Decision Processes 92, no. 1 (2003): 91-101.

Bush George, Phan Luu, and Michael I. Posner. (2000) "Cognitive and Emotional Influences in Anterior Cingulate Cortex." TICS 4(6):215-22.

Calder, Andrew J., Andrew D. Lawrence, and Andrew W. Young. (2001) "Neuropsychology of Fear and Loathing." Nature Reviews Neuroscience 2: 352-63 
Coghill, Robert C., Christine N. Sang, Jose Ma. Maisog, and Michael Iadarola (1999) "Pain intensity processing within the human brain: a bilateral, distributed mechanism” Journal of Neurophysiology 82:1934-1943.

Coghill, Robert C., Jeanne D. Talbot, Alan C. Evans, Ernst Meyer, Albert Gjedde, M. Catherine Bushnell, and Gary H. Duncan. (1994) “Distributed Processing of Pain and Vibration by the Human Brain." Journal of Neuroscience 14(7):4095-4108

Cox, Robert W. (1996) AFNI: Software for Analysis and Visualization of Functional Magnetic Resonance Images. Computational Biomedical Research 29:162-173.

Dhar, Ravi and Klaus Wertenbroch. (2000) “Consumer Choice Between Hedonic and Utilitarian Goods." Journal of Marketing Research 37(1): 60-71.

Duckworth, Kimberly L., John A. Bargh, Magda Garcia, and Shelly Chaiken. (2002) “The Automatic Evaluation of Novel Stimuli.” Psychological Science 13(6): 513-519.

Erk Suzanne, Manfred Spitzer, Arthur P. Wunderlich, Lars Galley, and Henrik Walter (2002) Cultural objects modulate reward circuitry. Neuroreport 13(18):2499-503.

Fazio, Russel H., David M. Sanbonmatsu, Martha C. Powell, Frank R. Kardes. (1986) “On the automatic activation of attitudes.” Journal of Personality and Social Psychology 50(2): 229-238.

Feldman Jack M. and John G. Lynch Jr. (1988). "Self-generated validity and other effects of measurement on belief, attitude, intention and behavior.” Journal of Applied Psychology, 73: 421-435.

Hare, Todd A., John O’Doherty, Colin F. Camerer, Wolfram Schultz and Antonio Rangel. (2008) "Dissociating the Role of the Orbitofrontal Cortex and the Striatum in the Computation of Goal Values and Prediction Errors." Journal of Neuroscience 28(22): 
5623-5630.

Hare, Todd A., Colin F. Camerer, Antonio Rangel (2009) "Self-Control in Decision-Making Involves Modulation of the vmPFC Valuation System." Science 324:646-648

Hsee, Christopher K., Yuval Rottenstreich and Zhixing Xiao (2005) “When Is More Better?: On the Relationship Between Magnitude and Subjective Value." Current Trends in Psychological Science 14:234-37. Hsee, Christopher K., Fang Yu, Jiao Zhang, and Yan Zhang (2003), "Medium Maximization," Journal of Consumer Research, 30(1), 1-14.

Johnson, Eric J., Gerald Häubl and Anat Keinan. (2007) “Aspects of Endowment: A Query Theory of Value Construction.” Journal of Experimental Psychology: Learning, Memory, and Cognition, 33: $461-474$.

Knutson, Brian, Charles M. Adams, Grace W. Fong, and Daniel Hommer. (2001) “Anticipation of Increasing Monetary Reward Selectively Recruits Nucleus Accumbens.” Journal of Neuroscience 21, RC159.

Knutson, Brian, Grace W. Fong, Shannon M. Bennett, Charles M. Adams and Daniel Hommer. (2003) “A Region of Mesial Prefrontal Cortex Tracks Monetarily Rewarding Outcomes: Characterization with Rapid Event-Related fMRI." NeuroImage 18(2):263-72.

Knutson, Brian, Scott Rick, G. Elliott Wimmer, Drazen Prelec, and George Loewenstein. (2007) "Neural Predictors of Purchases.” Neuron 53(1):147-56.

Knutson, Brian, G. Elliott Wimmer, Scott Rick, Nick G. Hollon, Drazen Prelec and George Loewenstein. (2008) "Neural Antecedents of the Endowment Effect." Neuron 58(5):814822.

Levy, Dino J. and Paul W. Glimcher. (2012) "The Root of All Value: A Neural Common Currency for Choice." Current Opinion in Neurobiology 22:1-12. 
Mantonakis, Antonia, Pauline Rodero, Isabelle Lesschaeve, and Reid Hastie. (2009) "Order in Choice Effects of Serial Position on Preferences." Psychological Science 20( 11): 13091312.

Okada, Erica M. (2005) "Justification Effects on Consumer Choice of Hedonic and Utilitarian Goods." Journal of Marketing Research 41(1):45-53.

Page Michael P.A. and Dennis Norris. (1998) The Primacy Model, a New Model of Immediate Serial Recall. Psychological Review 105(4):761-81.

Plassmann, Hilke, John O’Doherty, and Antonio Rangel. (2007) “Orbitofrontal Cortex Encodes Willingness-To-Pay in Everyday Economic Transactions.” Journal of Neuroscience. 27(37): 9984-9988.

Plassmann, Hilke, John O'Doherty, Baba Shiv and Antonio Rangel. (2008) “Marketing Actions Can Modulate Neural Representations of Experienced Pleasantness." Proceedings of the National Academy of Sciences. 105(3): 1050-4.

Plassmann, Hilke, John P. O’Doherty and Antonio Rangel (2010) “Appetitive and Aversive Goal Values Are Encoded in the Medial Orbitofrontal Cortex at the Time of Decision Making." Journal of Neuroscience. 30(32): 10799-808.

Pochon, J.B., Jason Riis, Alan G. Sanfey, L.E. Nystrom, J.D. Cohen. (2008) Functional Imaging of Decision Conflict. Journal of Neuroscience 28, 3468-3473.

Poldrack, Russell A., and Anthony Wagner. (2004) "What Can Neuroimaging Tell Us About the Mind? Insights from Prefrontal Cortex." Current Directions in Psychological Science. 13(5): 177-181.

Prelec, Drazen and George Loewenstein. (1998) “ The Red and the Black: Mental Accounting of Savings and Debt.” Marketing Science. 17(1): 4-28. 
Rao Akshay R., and Kent B. Monroe. (1989) “The Effect of Price, Brand Name, and Store Name on Buyers' Perceptions of Product Quality." J Marketing Res. 26(3):351-357.

Rick, Scott, Cynthia Cryder, and George Loewenstein. (2008) Tightwads and Spendthrifts. Journal of Consumer Research, 34 (6):767-82

Russo J. Edward, Margaret G. Meloy, and Victoria H. Medvec (1998) Predecisional Distortion of Product Information. J Marketing Res. 35(4):438-52.

Sacchet, Matthew, and Brian Knutson (2013) "Spatial Smoothing Systematically Biases the Location of Reward-Related Brain Activity.” NeuroImage 66:270-277.

Shiv, Baba, Ziv Carmon, and Dan Ariely. (2005) "Placebo Effects of Marketing Actions: Consumers Get What They Pay For.” Journal of Marketing Research, 42 (4): 383-93.

Simonson, Itamar and Aimee Drolet. (2004), “Anchoring Effects on Consumers’ Willingness-toPay and Willingness-to-Accept.” Journal of Consumer Research, 31 (3): 681-90.

Smith, David V., Benjamin Y. Hayden, Trong-Kha Truong, Allen W. Song, Michael L. Platt, and Scott Huettel. (2010) “ Distinct Value Signals in Anterior and Posterior Ventromedial Prefrontal Cortex.” Neuron, 30(7):2490-95.

Strahilevitz, Michal A. and John G. Myers (1998) "Donations to Charity as Purchase Incentives: How Well They Work May Depend on What You Are Trying To Sell." Journal of Consumer Research, 24: 434-46.

Squire, Larry R. (1992) Memory and the hippocampus: A synthesis from findings with rats, monkeys, and humans. Psychological Review 99:195-231.

Tavassoli, Nader T., and Yih Hwai Lee (2004), "The Effect of Attribute Order on Judgment in Chinese and English." Journal of Experimental Psychology:Applied, 10(4):258-266.

Thaler, Richard. (1999) “Mental Accounting Matters” Journal of Behavioral Decision Making 
12: $183-206$.

Tom, Sabrina M., Craig M. Fox, Christian Trepel, and Russell A. Poldrack. (2007) The Neural Basis of Loss Aversion in Decision-Making Under Risk Science 315(5811): 515-518.

Weber, Elke U., Eric J. Johnson, Kerry F. Milch, Hannah Chang, Jeffrey Brodscholl, and Daniel G. Goldstein. (2007) “Asymmetric Discounting in Intertemporal Choice: A Query Theory Account." Psychological Science, 18(6): 516-523.

Waber, Rebecca L., Baba Shiv, Ziv Carmon, Dan Ariely. (2008) “Commercial Features of Placebo and Therapeutic Efficacy.” Journal of the American Medical Association 299(9): 1016-7.

Wyer Robert S. and Thomas K. Srull. (1986.) Human Cognition in its Social Context. Psychological Review 93(3):322-59.

Yeung, Catherine W.M. and Robert S.Wyer (2004) Affect, Appraisal and Consumer Judgment. Journal of Consumer Research 31(2): 412-24.

Zajonc, Robert (1980) "Feeling and thinking : Preferences need no inferences." American Psychologist 35(2): 151-175. 
TABLE 1

Whole Brain Activity Patterns for Price Differential and Preference

(Predicted areas in bold)

Talaraich Coordinates

\begin{tabular}{|c|c|c|c|c|}
\hline Peak Z & $\begin{array}{l}\text { Cluster } \\
\text { Size } \\
\text { (Voxels) }\end{array}$ & $\begin{array}{c}\text { Right } \\
(x)\end{array}$ & $\begin{array}{c}\text { Anterior } \\
\text { (y) }\end{array}$ & $\begin{array}{c}\text { Superior } \\
(z)\end{array}$ \\
\hline
\end{tabular}

Price differential

\begin{tabular}{lccccc}
\hline $\begin{array}{l}\text { Medial Prefrontal } \\
\text { Cortex }\end{array}$ & $\begin{array}{c}4.49 \\
\text { (SVC) }\end{array}$ & (3) & $-/+2$ & -49 & 0 \\
Frontal Gyrus & 4.16 & 5 & 4 & -68 & 1 \\
\hline
\end{tabular}

Preference

Left Middle Occipital

Gyrus

3.98

4

$-34$

75

12

Right Caudate and

Nucleus Accumbens

$\begin{array}{lllll}4.67 & 16 & 8 & -8 & 4\end{array}$

Left Caudate and Nucleus Accumbens

$\begin{array}{lllll}4.34 & 7 & -11 & -11 & 12\end{array}$

Right Middle Frontal

Gyrus

3.54

4

30

$-22$

46

Bilateral Medial Frontal

Gyrus, including

4.63

27

0

$-26$

38

Anterior Cingulate

Left Middle Frontal

Gyrus

3.68

4

$-22$

$-30$

42

Left Medial Frontal

Gyrus

3.63

4

$-38$

42

Right Ventrolateral

Prefrontal Cortex

3.97

5

34

$-41$

$-7$ 
TABLE 2

Difference-in-Differences Regressions for MPFC and NAcc Activity During Period 2.

\begin{tabular}{lcccc} 
MPFC activity (\#observations = 1360) & B & SE & $\mathbf{Z}$ & $\mathbf{p}$ \\
\hline Constant & .059 & .051 & 1.15 & .249 \\
\hline Condition (product or price primacy) & -.50 & .027 & -1.79 & .074 \\
\hline Purchase (yes or no) & .009 & .037 & .22 & .822 \\
\hline Interaction (ConditionXPurchase) & .11 & .053 & $\mathbf{2 . 1 0}$ & .036 \\
\hline Participants with significant fixed effects (out of 17) & $=5(p<.05)$ \\
\hline
\end{tabular}

\begin{tabular}{lcccc} 
NAcc activity (\#observations = 1360) & B & SE & $\mathbf{Z}$ & $\mathbf{p}$ \\
\hline Constant & .0286 & .032 & .90 & .386 \\
\hline Condition (product or price primacy) & -.044 & .017 & -2.55 & .01 \\
\hline Purchase (yes or no) & .0899 & .23 & 3.83 & $<.001$ \\
\hline Interaction (ConditionXPurchase) & .014 & .032 & .45 & .652 \\
\hline Participants with significant fixed effects (out of 17) $=2(p<.05)$ & & \\
\hline
\end{tabular}


TABLE 3

Practical/Frivolous Categorization of Utilitarian Products

\begin{tabular}{|l|l|c|c|}
\hline & \multicolumn{1}{|c|}{ Product Primacy } & Price Primacy \\
\hline & $\begin{array}{l}\text { (\% rated practical + } \\
\text { practical and frivolous) }\end{array}$ & $\begin{array}{l}\text { (\% rated practical + } \\
\text { practical and frivolous })\end{array}$ \\
\hline & Water Filtration Pitcher & $90 \%$ & $90 \%$ \\
\hline AA Batteries & $95 \%$ & $100 \%$ \\
\hline 8 GB USB Drive & $93 \%$ & $90 \%$ \\
\hline & Mini Flashlight & $95 \%$ & $93 \%$ \\
\hline \multicolumn{2}{|c|}{} \\
\hline
\end{tabular}




\section{FIGURE 1}

\section{FMRI SHOPPING TASK}

Product primacy: Participants viewed the labeled product first (period 1, 4s), followed by the product together with its price (period 2, 4s), then were prompted to choose (period 3, 4s). Price primacy: Participants viewed price first (period 1, 4s); trials then proceeded as in the product primacy condition.

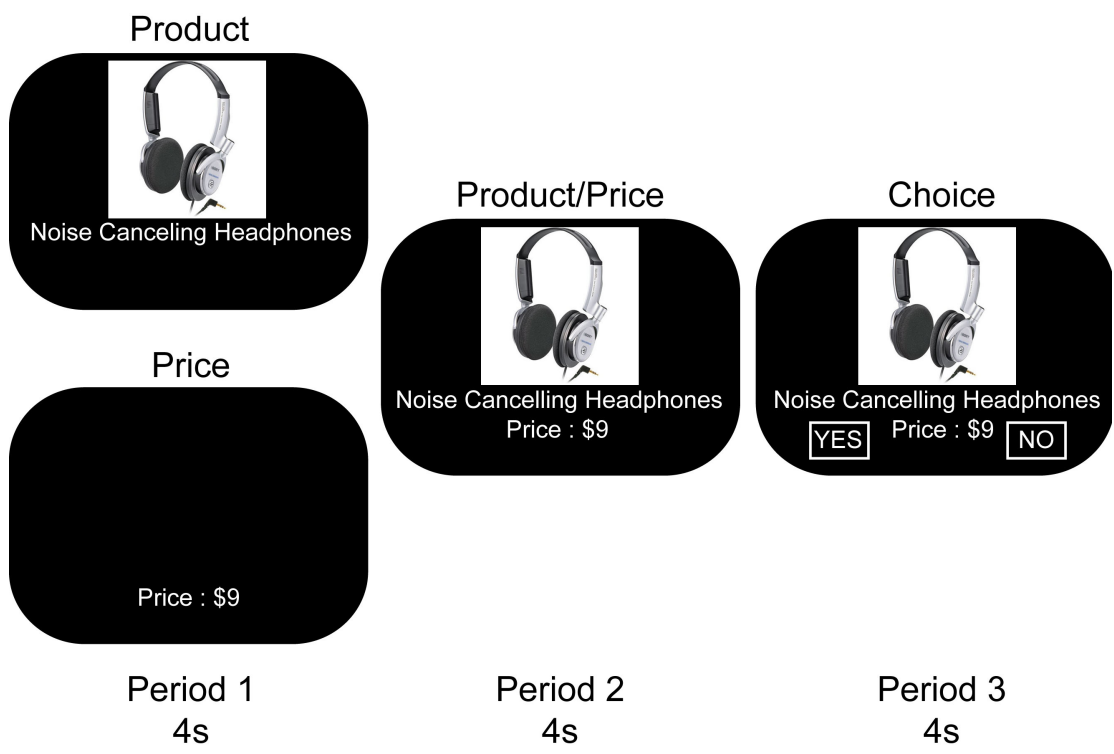


FIGURE 2

\section{MPFC ACTIVITY AND PRICE DIFFERENTIAL}

A. Brain activity associated with price differential (whole brain analysis). B. MPFC timecourses averaged across all price (gray) and product (black) primacy trials. (n.b. onsets lagged by $4 \mathrm{~s}$ to accommodate hemodynamic response.) C. MPFC timecourses for purchased (blue) versus and unpurchased (red) items. During Period 1 (p1) participants viewed product alone for product-first trials, and price alone for price first trials. During Period 2 (p2) participants viewed product and price together, and during Period 3 (p3) they were prompted to choose whether or not to purchase. The first timepoint in Period 1 indicates the onset of the trial D. Unpurchased products: comparison of MPFC activity during price-first (gray) and product-first (black) trials. $\left({ }^{*} p<.05\right)$

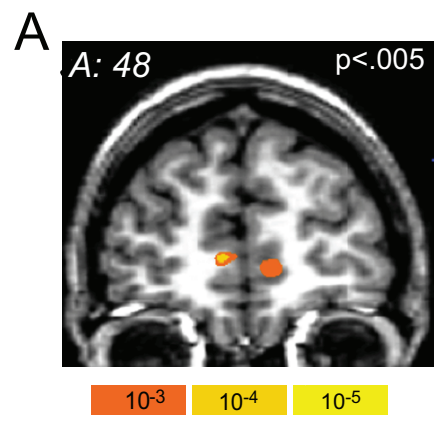

C

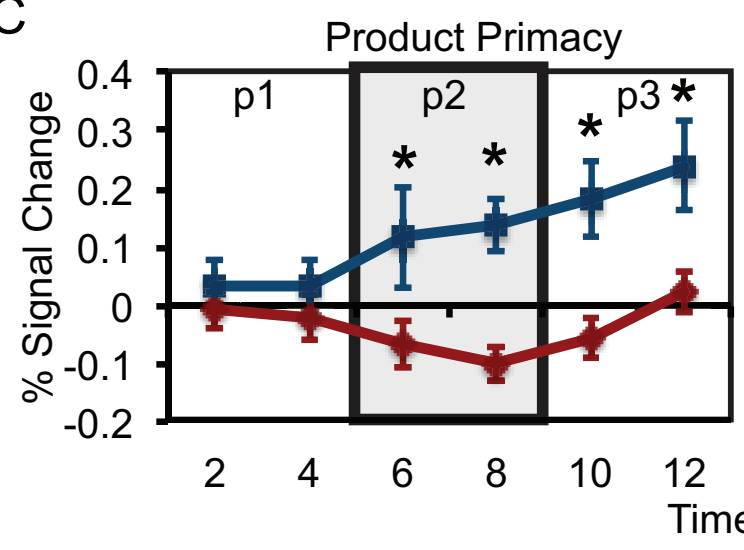

D

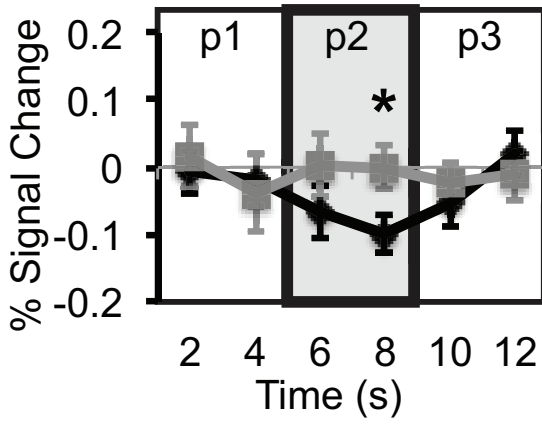

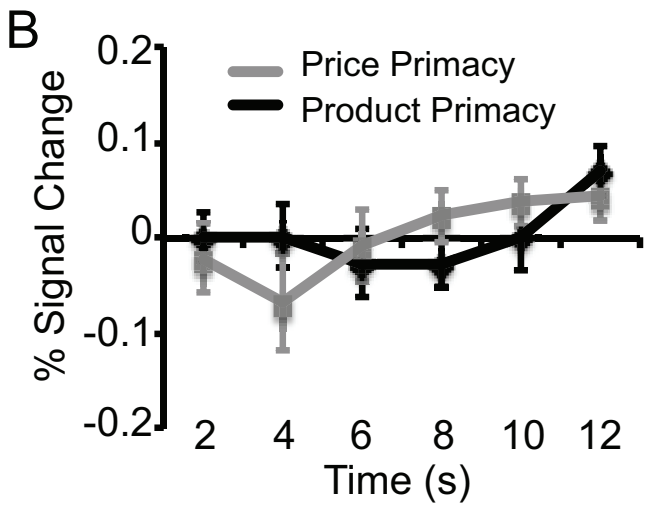

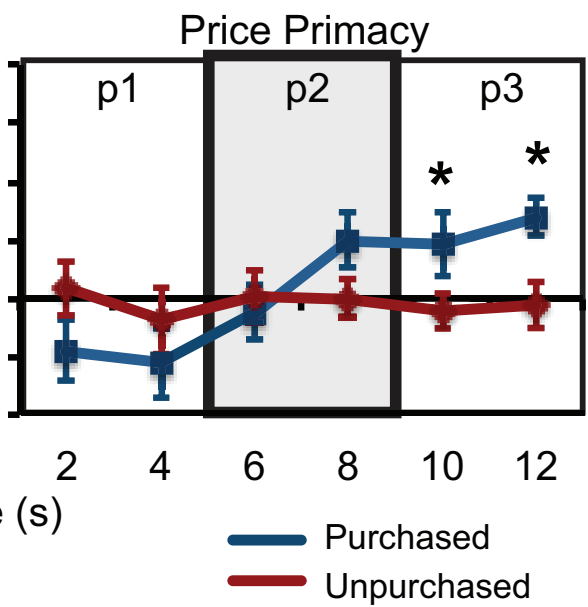

$\longrightarrow$ Price Primacy Product Primacy 


\section{FIGURE 3}

\section{NACC ACTIVITY AND LIKING}

A. Whole brain activity associated with liking. B. NAcc timecourses averaged across all price (gray) and product (black) primacy trials. C. NAcc timecourses for purchased (blue) versus unpurchased (red) products. During Period 1 (p1) participants viewed product alone for productfirst trials, and price alone for price first trials. During Period 2 (p2) participants viewed product and price together, and during Period 3 (p3) they were prompted to choose whether or not to purchase. The first timepoint in Period 1 indicates the onset of the trial $\quad$ D. Unpurchased products: comparison of NAcc activity during product-first (gray) and price-first (black) trials. $\left({ }^{*} p<.05\right)$

A

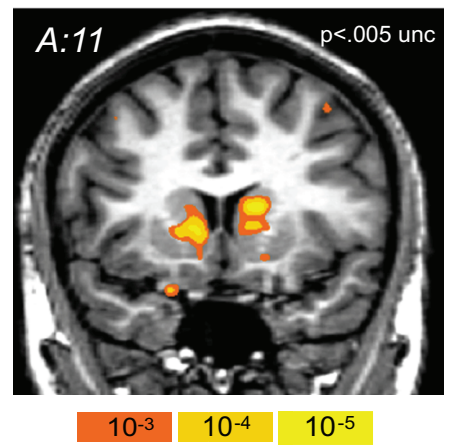

C

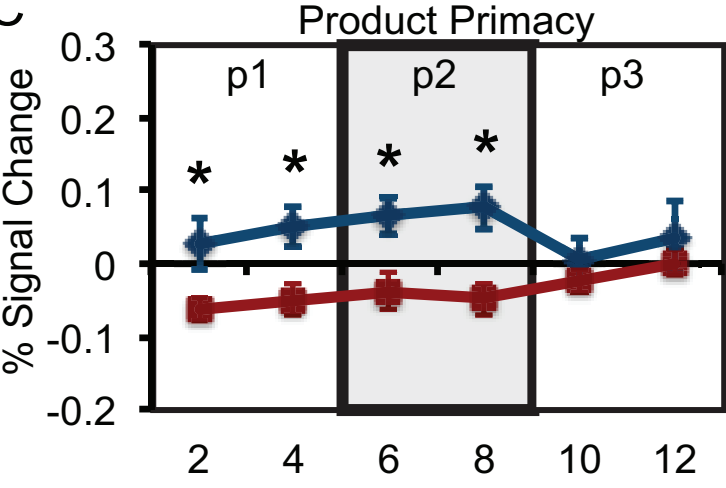

D

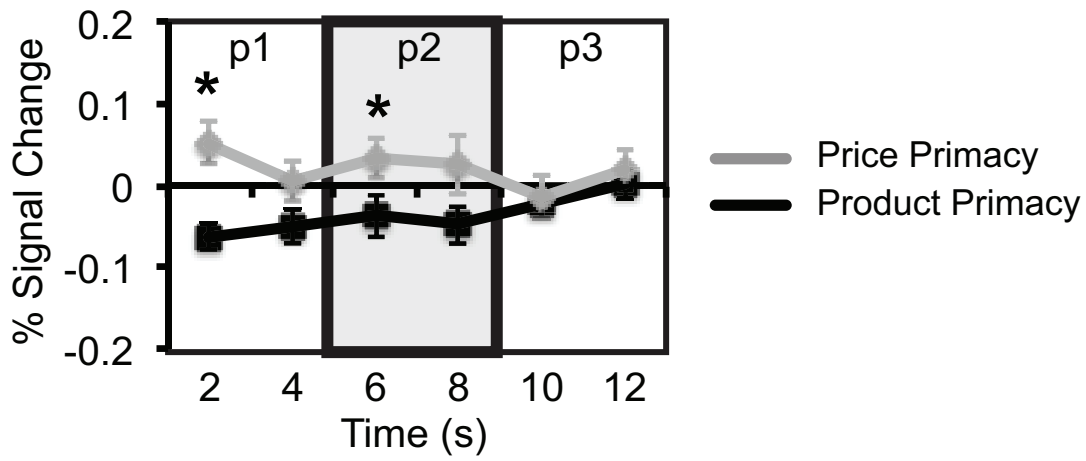

Time

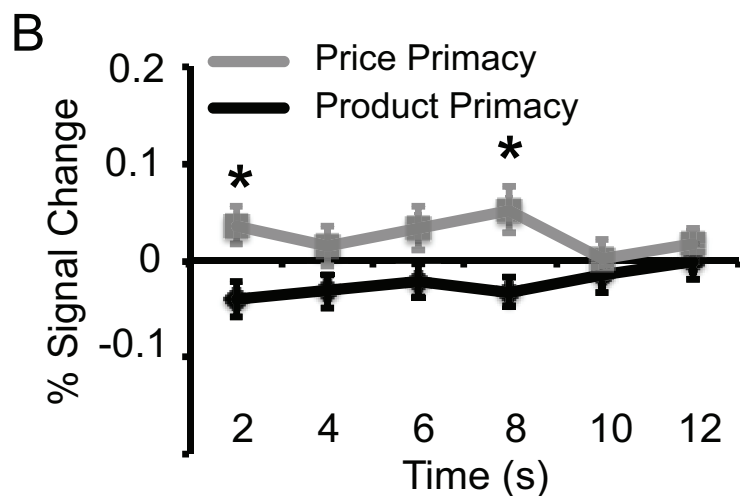

Time (s)

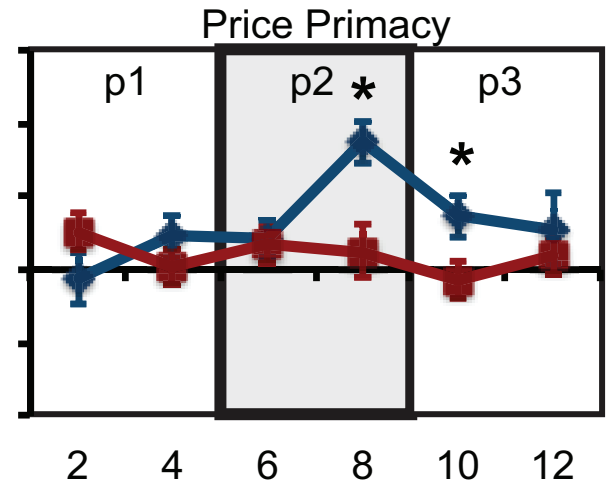

(s)

Purchased

Unpurchased 
FIGURE 4

\section{PRICE PRIMACY AND UTILITARIAN PURCHASES}

A. Price primacy increases average number of purchases. B. Price primacy increases the percent of purchases made from items that had positive price differentials. $\left({ }^{* *} p<.01\right)$

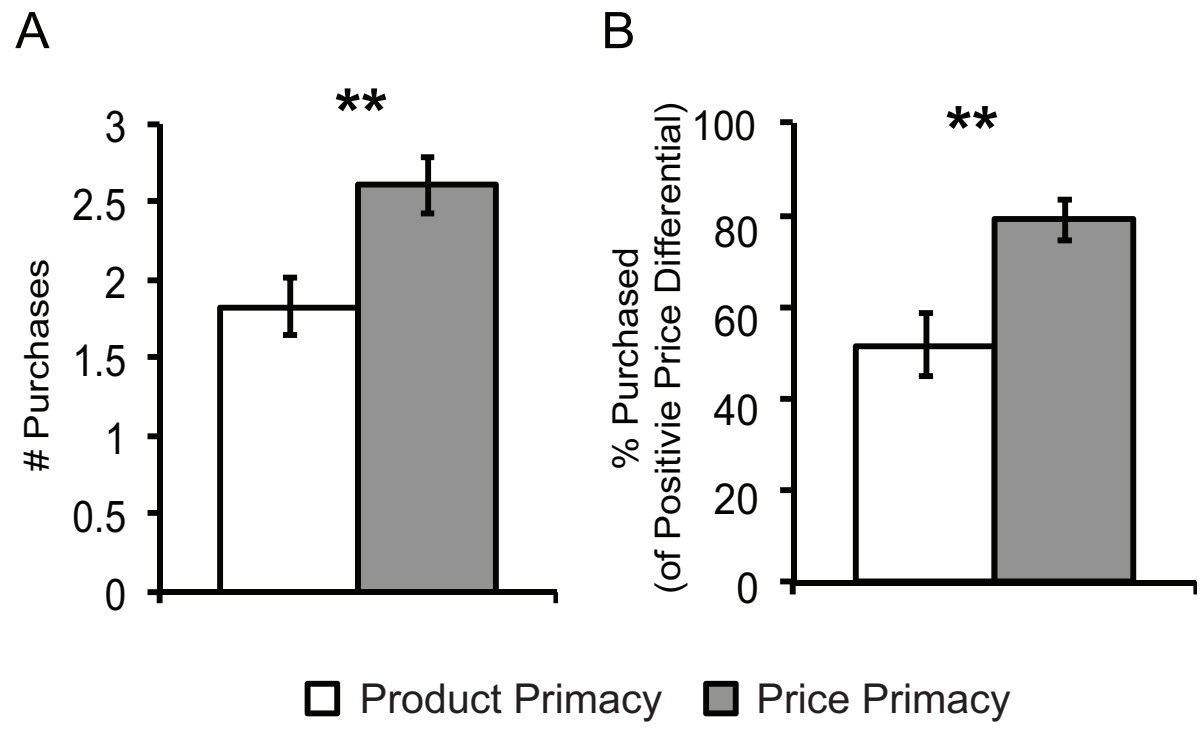




\section{APPENDIX: Price Primacy, Insula, and the Pain of Paying}

Previous research on shopping decisions has found that activity in the insula-a brain area associated with anticipation of pain (e.g. Coghill et al. 1994, 1999), negative emotions like disgust (Calder et al. 2001) and monetary loss (Paulus and Stein 2006)-is negatively correlated with purchasing behavior (Knutson et al. 2007). In particular, the study found that insula activity increased when individuals rejected an item for purchase, and when prices were perceived to be excessive. This has been interpreted as support for a pain-of-paying account in which prices, as representations of loss, have an impact similar or equal to physical pain (Prelec and Loewenstein 1998; Rick et al. 2008). Such findings might suggest that being exposed to potential costs or excessive prices in the current study should evoke an insula response as well. However, whole brain analysis examining activations correlated with price differential revealed no significantly correlated activity in the insula (confirmed with exploratory analyses that allowed a statistical threshold as lenient as $p<.01$, uncorrected). Activation timecourses were averaged and extracted to further examine insula activity from focal volumes of interest (Talairach coordinates : $\pm 32,9$, 9) under price and product primacy conditions to allow direct comparisons to earlier findings (Knutson et al., 2007). These analyses indicated that insula activity did not significantly discriminate between purchased and unpurchased items at any point during the trials for either condition (Appendix B Figure 1).

Given that we were not able to replicate this particular insula finding of Knutson et al. (2007) despite using an identical paradigm and the same incentives, it is useful to consider the possibility that the design of the primary analysis model did not capture the relevant insula activity. This could have been because variance related to price was entirely modeled as part of 
the price differential regressor. Instead, one could include price in the model as a parametric representation of the specific prices that participants viewed during each trial of the experiment. Thus, we constructed two variants of the original model. In the Period 2 model, a regressor representing the mean-centered price of the item offered on each trial replaced the price differential regressor from the primary analysis. As the label suggests, brain activity was still modeled during period 2, when both price and product information were visible on the screen in all trials. A second First 4 model also used a mean-centered offered price regressor, but price was modeled during the first four seconds that it appeared on a trial-by-trial basis. Thus in price primacy trials, price was modeled during period 1, but in product primacy trials, it was modeled during period 2 .

Areas of activation correlating with price were qualitatively similar between models, as can be seen in Appendix Figure 2. In both cases, activation was seen in the right anterior insula and dorsolateral prefrontal cortex (see Appendix Table 1 for a complete list of activations from the Period 2 model). Though insula activity is commonly interpreted as relating to pain or negative emotions, activity in the anterior portion of the insula has also been shown to correlate with general arousal and salience (Critchley et al. 2000; Knutson and Greer2008; Bartra et al. 2013). Thus one cannot infer whether increases in activity at the observed location are specifically due to increased feelings of anticipated loss or more generally due to increased feelings of arousal (good or bad) in response to high prices. Furthermore, it may be relevant that the activations revealed by these models are significantly more anterior from the loss-related regions previously identified (Knutson et al. 2007). Overall, the current data cannot provide conclusive evidence one way or the other to speak to the role of insula activity in pain of paying in this version of the purchasing task. 


\section{References}

Bartra, Oscar, Joseph T. McGuire, and Joseph W. Kable. (2013) "The valuation system: A coordinate-based meta-analysis of BOLD fMRI experiments examining neural correlates of subjective value." NeuroImage 76: 412-27.

Calder, Andrew J., Andrew D. Lawrence, and Andrew W. Young. (2001) "Neuropsychology of Fear and Loathing." Nature Reviews Neuroscience 2: 352-63.

Coghill, Robert C., Christine N. Sang, Jose Ma. Maisog, and Michael Iadarola (1999) "Pain intensity processing within the human brain: a bilateral, distributed mechanism” Journal of Neurophysiology 82:1934-1943.

Coghill, Robert C., Jeanne D. Talbot, Alan C. Evans, Ernst Meyer, Albert Gjedde, M. Catherine Bushnell, and Gary H. Duncan. (1994) "Distributed Processing of Pain and Vibration by the Human Brain.” Journal of Neuroscience 14(7):4095-4108.

Critchley, Hugo D., Rebecca Elliott, Christopher J. Mathias, and Raymond J. Dolan. (2000) “ Neural Activity Relating to Generation and Representation of Galvanic Skin Conductance Responses: A Functional Magnetic Resonance Imaging Study.” Journal of Neuroscience 20(8):3033-3040.

Knutson, Brian, and Stephanie M. Greer. (2008) "Anticipatory affect: neural correlates and consequences for choice." Philosophical Transactions of the Royal Society B: Biological Sciences 363.1511: 3771-3786.

Knutson, Brian, Scott Rick, G. Elliott Wimmer, Drazen Prelec, and George Loewenstein. (2007) “Neural Predictors of Purchases." Neuron 53(1):147-56. 
Paulus, Martin P. and Murray B. Stein (2006) An insular view of anxiety. Biological Psychiatry, 60:383-387.

Prelec, Drazen and George Loewenstein. (1998) “ The Red and the Black: Mental Accounting of Savings and Debt." Marketing Science. 17(1): 4-28.

Rick, Scott, Cynthia Cryder, and George Loewenstein (2008) Tightwads and Spendthrifts.

Journal of Consumer Research, 34 (6):767-82 


\section{APPENDIX TABLE 1}

Activation Foci for Period 2 (Price) Model

\section{Talairach Coordinates}

\begin{tabular}{lcccc} 
& Peak Z & $\begin{array}{c}\text { Right } \\
(\mathbf{x})\end{array}$ & $\begin{array}{c}\text { Anterior } \\
(\mathbf{y})\end{array}$ & $\begin{array}{c}\text { Superior } \\
(\mathbf{z})\end{array}$ \\
\hline Price (orthogonalized) & & & & \\
\hline Left Cuneus & 3.70 & -11 & 86 & 19 \\
Right Cuneus & 3.44 & 8 & 82 & 8 \\
Right Precuneus & 3.71 & 34 & 79 & 34 \\
Right Superior Parietal Lobule & 3.78 & 30 & 68 & 53 \\
Left Middle Occipital Gyrus & 3.60 & -38 & 56 & 42 \\
Bilateral Parahippocampal & $4.65(3.86)$ & $+/-30$ & $49(45)$ & $-3(1)$ \\
Gyrus & 3.44 & 52 & 45 & 4 \\
Right Inferior Parietal Lobule & 3.748 & 4 & 34 & 42 \\
Right Posterior Cingulate Cortex & $\mathbf{5 . 2 2}$ & $\mathbf{- 2 5}$ & $\mathbf{2 3}$ & $\mathbf{3}$ \\
Right Insula & $\mathbf{( S V C )}$ & & 22 & -7 \\
Right Middle Temporal Gyrus & 3.67 & 56 & -19 & 46 \\
Right Dorsolateral Prefrontal & 3.94 & 34 & -49 & 38 \\
Cortex & 3.98 & 15 & &
\end{tabular}




\section{APPENDIX FIGURE 1}

Insula Activity For Unpurchased (Blue) and Purchased (Red) Items.

(Event onsets lagged by 4s)

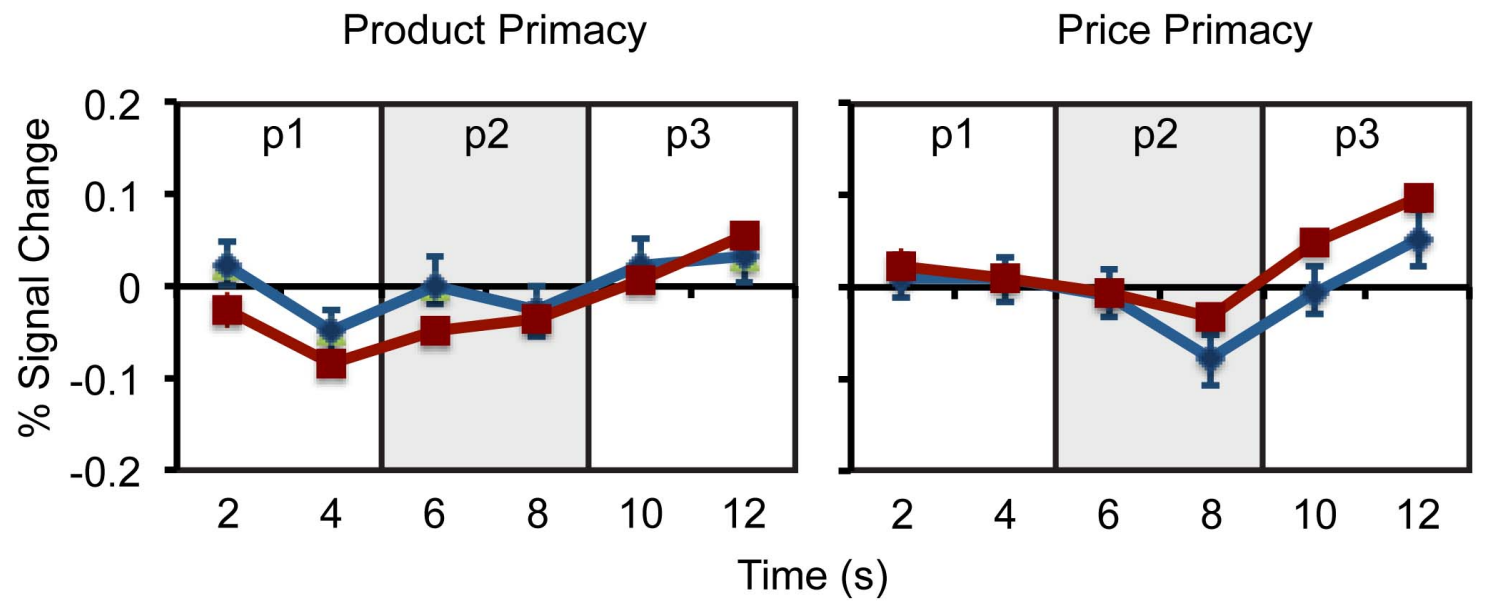




\section{APPENDIX FIGURE 2}

Whole Brain Activation Maps for First 4 and Period 2 Models

First 4 Model

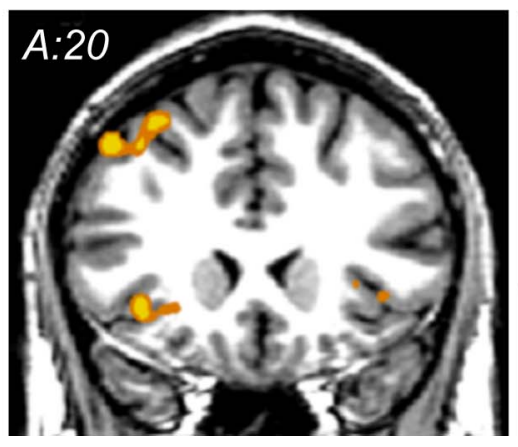

Period 2 Model

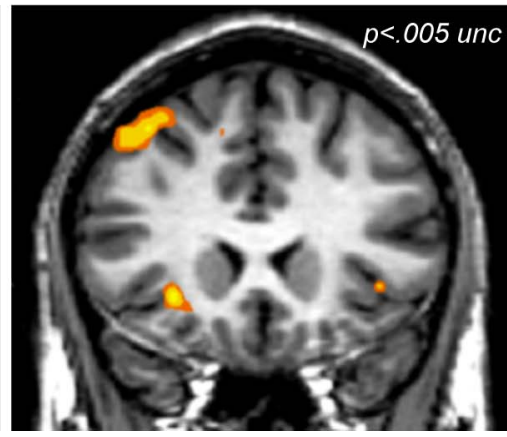

$10^{-5}$

$10^{-4}$

$10^{-3}$ 


\section{WEB APPENDIX}

\section{FMRI Methods Supplement}

Acquisition: Images were acquired with a 1.5-T General Electric MRI scanner using a standard birdcage quadrature head coil. Twenty-four four-millimeter-thick slices (in-plane resolution $3.75 \times 3.75 \mathrm{~mm}$, no gap) extended axially from the mid-pons to the top of the skull to provide whole-brain coverage and acceptable coverage of subcortical areas of interest.

Functional scans were acquired with a $\mathrm{T} 2 *$-sensitive spiral in-/out- pulse sequence $(\mathrm{TR}=2 \mathrm{~s}, \mathrm{TE}$ $=40 \mathrm{~ms}$, flip $=90$ degrees $)$ designed to minimize signal dropout at the base of the brain (Glover and Law 2001). High-resolution structural scans were acquired using a T1-weighted spoiled grass sequence $(\mathrm{TR}=100 \mathrm{~ms}, \mathrm{TE}=7 \mathrm{~ms}$, flip $=90$ degrees $)$.

Analysis: Maps of contrast coefficients for regressors of interest were transformed into Zscores, coregistered with individual structural maps, spatially normalized by manually warping to Talairach space and slightly spatially smoothed to minimize effects of anatomical variability. Smoothing kernel size $(\mathrm{FWHM}=4 \mathrm{~mm})$ was selected to appropriately detect activity in subcortical structures (Sacchet and Knutson 2013). Maps were then collectively submitted to a one-sample t-test against the null hypothesis of no activation to test for a group difference while controlling for random effects. Whole brain maps were thresholded at $\mathrm{p}<.001$ (uncorrected) to identify significant spatial areas of activation, with a cluster threshold of four $4 \mathrm{~mm}$ cubic voxels (256 mm cubic; conservatively defined as "faces must touch", alpha level of .001). For MPFC activity, small volume correction was used to confirm activation based on functionally selected activity peaks (maximum beta). 